\title{
Radiofarmácia e radiofármacos no Brasil: aspectos sanitários e fabris para a construção de uma linha de produção de radiofármacos PET
}

\author{
Ralph Santos Oliveira, Clayton Augusto Benevides, Suy Ferreira Hwang, \\ Roberto Paulo Câmara Salvi, Ione Maria Acioly Teixeira Ricarte de Freitas
}

\author{
Divisão de Produção de Radiofármacos, Comissão Nacional de Energia Nuclear, \\ Centro Regional de Ciências Nucleares do Nordeste
}

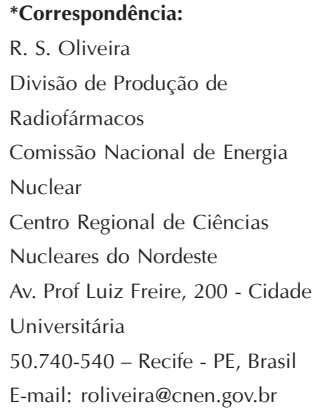

\section{INTRODUÇÃO}

De acordo com Mather (2001), Radiofarmácia é cientificamente reconhecida como essencial para a Medicina Nuclear. Sem os radiofármacos, procedimentos radiodiagnósticos ou radioterapêuticos não poderiam ser realizados através da Medicina Nuclear. Os radiofármacos em uso corrente no mundo são os mesmos, salvas algumas exceções relacionadas ainda à pesquisa e ao desenvolvimento de novos radiofármacos. Segundo Tewson e Krohn (1998), os radiofármacos são utilizados como substâncias marcadas para observar alterações fisiológicas e/ou distribuição anormal de um determinado composto administrado em um ser vivo, ou ainda como compostos de ação terapêutica na clínica médica.

A preparação de um produto final radiativo, a preparação da dose a ser administrada e a administração dessa dose ao paciente devem ser feitas no menor intervalo de tempo possível. Assim, todas essas etapas devem respeitar parâmetros de qualidade e eficácia. Para tanto, profissionais devidamente treinados e capacitados devem realizar as etapas dessa tarefa. Sendo assim, deve-se observar o enuncia- do de Fallais, Siverwright e Ogle (1997), que considera fundamental a oficialização do profissional radiofarmacêutico assim como a inclusão dessa disciplina na grade curricular do curso de Farmácia de forma a se obter profissionais aptos a trabalharem com esse tipo de medicamento.

A produção de radiofármacos $\mathrm{PET}$ tem várias peculiaridades e envolve dois aspectos fundamentais: a proteção radiológica e o trabalho em condições especiais de assepsia e controle ambiental. O manuseio de radiofármacos PET é potencialmente perigoso, devido às suas características radioativas, contudo o nível de risco depende particularmente da emissão de radiação e do tempo de meia-vida do radionuclídeo usado. Atenção especial deve ser dada ao risco da contaminação cruzada, assim como ao rejeito produzido no final de cada linha de produção, ambos de suma importância para a elaboração de uma linha de produção de radiofármacos. Por serem medicamentos injetáveis, os radiofármacos PET devem cumprir com todas as condições exigidas aos medicamentos estéreis; para tanto o ambiente de produção e controle de qualidade devem ser classificados e monitorados. A manutenção dos parâmetros aceitáveis de controle ambiental, assim como das especificações do pro- 
duto final, é feita utilizando-se de vários recursos e equipamentos, dentre eles: fluxo laminar e filtros de ar HEPA (High Efficiency Particulate Air), além de procedimentos de limpeza e esterilização adequados e pertinentes à manutenção da assepsia e da classificação das salas limpas, e do produto final (Westera, 2003).

A produção conta ainda com rigoroso controle de processo (realizado em todas as etapas críticas da produção do radiofármaco PET como, por exemplo, no envase do produto acabado), que deve ser feito preconizando a não contaminação cruzada, o menor grau de exposição do operador e a eficácia do produto final. O controle de qualidade por sua vez inclui: integridade da embalagem do produto final, pureza radioquímica e esterilidade entre outros. Todos esses parâmetros devem ser rigorosamente analisados, para tanto se faz o uso de técnicas rotineiras de análise, a saber: Cromatografia Líquida de Alta Resolução, Cromatografia Gasosa e Teste de Esterilidade e Apirogenicidade (Oliveira, 2006; Tochon-Danguy et al. 1999).

Uma das principais características dos radiofármacos, em especial dos radiofármacos PET, é sua independência da massa. Neste tipo de fármaco, a sua principal característica está expressa em atividade e não em uma concentração massa-dependente (Finn,1999). Tal fato conduz a outro tipo de problema que tem reflexos diretos na sua regulamentação legislativa, que é a produção de lotes. De acordo com Finn (1999), um lote de radiofármacos PET pode representar apenas uma dose de produto acabado.

O objetivo deste trabalho é propor parâmetros estruturais, baseados nas legislações sanitárias vigentes para medicamentos, ou uma referência nacional básica, de estrutura física de uma linha de produção de radiofármacos PET, de modo a cumprir as exigências legais tanto no âmbito da vigilância sanitária, como o de segurança radiológica e de Boas Práticas de Fabricação (BPF) de medicamentos injetáveis.

\section{MATERIAL E MÉTODOS}

A metodologia utilizada foi a realização de análise dos padrões de qualidade nacionais e internacionais referente às BPF's (Boas Práticas de Fabricação) de medicamentos injetáveis, assim como das normas nacionais de vigilância sanitária, em especial a RDC (Resolução de Diretoria Colegiada) 210/03 e as normas de segurança e proteção radiológica, assim como segurança do trabalho. A análise foi realizada sobre a planta baixa da Divisão de Produção de Radiofármacos do Centro Regional de Ciências Nucleares em fase de implantação.

Os parâmetros foram separados por categoria e especialidade e grupos de especialistas ficaram responsáveis pela avaliação da planta de acordo com os parâmetros estipulados.

As normas utilizadas para a análise da planta foram: Série ISO (International Standards Organization) 9000, 14000, 18000, a série OHSAS (Occupational Health and Safety Assessment Series) em especial a 18001, as leis sanitárias, em especial a RDC 210/03 da ANVISA (Agência Nacional de Vigilância Sanitária), e as normas da CNEN (Comissão Nacional de Energia Nuclear) de instalações radiativas e segurança radiológica: NE-6.02, NE6.05, NE-6.06, NE-6.09, NE-5.01 e NN-3.01, NE-2.01

Os grupos formados foram divididos por suas diversas especialidades, a saber: físicos, engenheiros (civil, elétrico, segurança do trabalho, hidráulico e químico) e farmacêuticos. Cada grupo ficou responsável pela análise de acordo com sua especialidade e tendo como base as normas nacional ou internacional referente a sua especialidade.

Embora diversos grupos tenham participado e feito suas análises, a parte farmacêutica, neste trabalho, será a descrita devido principalmente a sua relevância sanitária e a falta, até o momento, de legislação específica.

\section{RESULTADOS E DISCUSSÃO}

A planta baixa analisada (Figura1) e resultado do estudo dos grupos formados teve diversos pontos relevantes questionados, em especial quanto a área farmacêutica (grupo farmacêutico). O primeiro deles foi referente ao controle de qualidade do produto acabado.

De acordo com a RDC210/03 no sub-ítem 11.3.5 e 11.3.6, corroborado pelo seu ítem 3 (Controle de Qualidade) sub-ítem 3.2 letra h:

"[...] amostras suficientes das matérias-primas e dos produtos terminados devem ser retiradas, a fim de que, se necessário, possam ser feitos exames futuros do produto, as amostras retidas de produto terminado devem ser mantidas em suas embalagens finais, nas condições de armazenamento estabelecidas, a menos que as mesmas sejam excepcionalmente gran$\operatorname{des}[\ldots]$,

Esta exigência formal remete à necessidade de uma sala de contra-provas no projeto fabril, entretanto, embora seja um ítem formal, não se aplica a instalações de produção de radiofármacos PET, pois os produtos acabados não ultrapassam a quantidade de alguns mililitros e com um "prazo de validade" de, no máximo, alguns dias.

No tocante ainda ao seu ítem 13.10 (Padrões de Referência) corroborado pelo ítem 3 (Controle de Qualidade), sub-ítem 3.3: 
"[...] O controle de qualidade tem ainda outras atribuições, tais como: estabelecer, validar e implementar seus procedimentos para avaliar, manter e armazenar os padrões de referência [...]

Os produtos radiofarmacêuticos não possuem ainda nenhum padrão de referência nacional, o que é mais um obstáculo ao cumprimento da norma para linhas de produção de radiofármacos e radiofármacos PET.

Conforme consta na RDC 210/03 no seu sub-ítem 11.6.1, 11.6.2 e 11.6.3, os laboratórios de controle de qualidade requerem especial atenção, principalmente quanto à segregação e manutenção das condições de limpeza. Embora em uma linha de produção de radiofármacos $\mathrm{PET}$, a produção ocorra em um ambiente segregado dos demais, nos seus módulos de síntese (cabines blindadas), ainda assim, foi estabelecido a segregação física entre o local de posicionamento dos módulos de síntese e a área responsável pelo controle de qualidade, de modo a se prevenir os riscos de contaminação cruzada. De maneira suplementar à norma vigente, foi estabelecido a segregação entre os dois controle de qualidade, a saber: físico-químico e microbiológico, desta forma assegurando a qualidade do produto acabado.

Outro ponto bem discutido também foi o referente a equipamentos. Estes, de acordo com a Legislação Brasileira, devem ser projetados, construídos, adaptados, instalados, localizados e mantidos de forma a facilitar as operações a serem realizadas. Seguindo estas orientações, o grupo farmacêutico estabeleceu as posições dos equipamentos de forma a reduzirem a interferência elétrica, mecânica e magnética; para tanto, bancadas especiais revestidas com PVP (polivinilpir- rolidona) e rede elétrica própria foram desenvolvidas. Desta forma, pretende-se minimizar os riscos de erros e interferência externa, assim como permitir a limpeza adequada.

Em relação ao tópico 11.1 (Generalidades) da legislação nacional, especial atenção foi dispensada, de modo a se obter o melhor resultado possível. Neste sentido, cada sub-ítem foi devidamente analisado e as operações resultantes dessa análise encontram-se abaixo discriminadas.

O sub-ítem 11.1.3, que versa sobre a limpeza das instalações, várias medidas foram tomadas de forma a se obter o melhor resultado, que no caso em tela representava a melhor forma de se alcançar padrões de limpeza. Neste sentido, foi utilizado material resistente à água e com alta resistência a produtos sanitizantes em especial o cloro (hipoclorito de sódio), o que representou a opção pelo uso da tinta epóxi em paredes e pisos. Ainda de forma a se maximizar o processo de limpeza, tetos rebaixados com forro de PVC (cloreto de polivinil) e lâmpadas embutidas em campânula de vidro foram escolhidas.

Quanto ao sub-ítem 11.1.5, sistema de ar-condicionado central com filtragem por filtros de alto desempenho (HEPA) nas salas de produção e controles de qualidade foram preferidos, por apresentarem maior eficácia, principalmente relativo a sua higienização e controle dos filtros quando comparados com os aparelhos de ar-condicionado individuais. A iluminação escolhida foi a com luzes fluorescentes embutidas, protegidas por campânula de vidro (menor adesão de sujeira e maior facilidade de limpeza).

O sub-ítem11.1.6 foi contemplado fazendo-se uma tubulação sifonada, desta forma a entrada de vetores é reduzida em $90 \%$ dos casos.

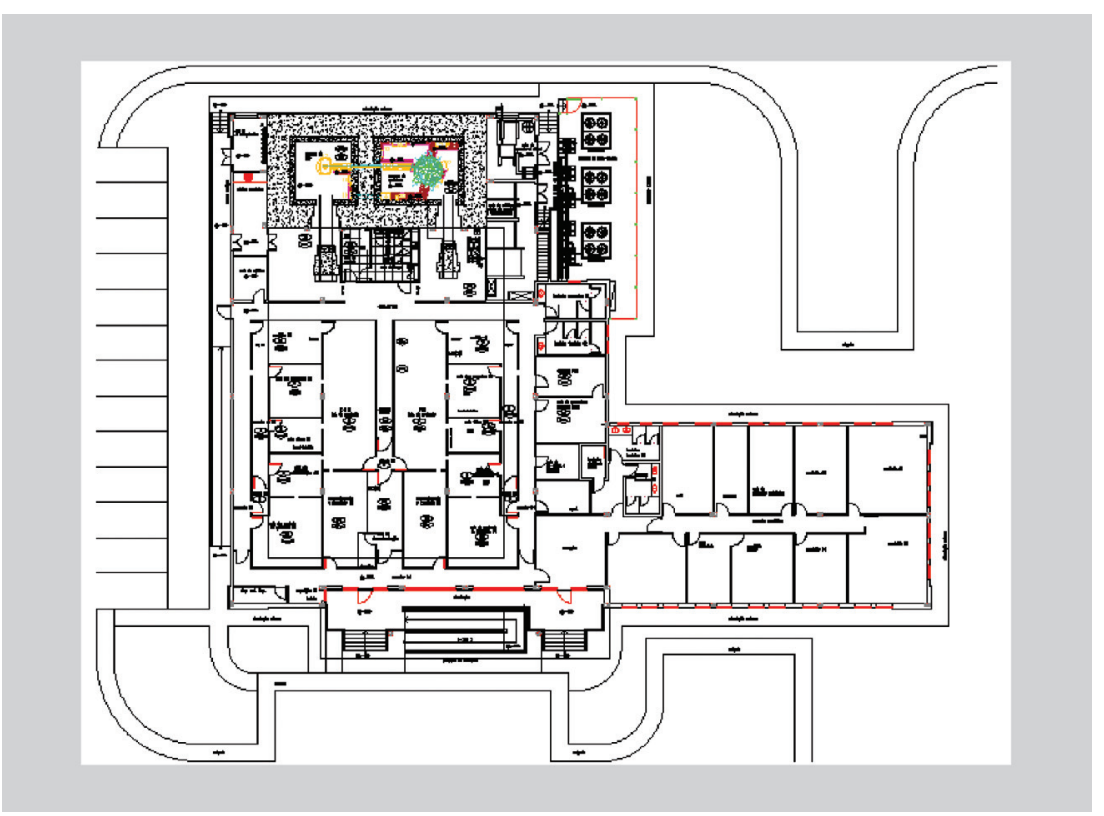

FIGURA 1 - Planta baixa projeto fabril da linha de produção de radiofármacos. Fonte: CNEN/CRCN, 2007. 


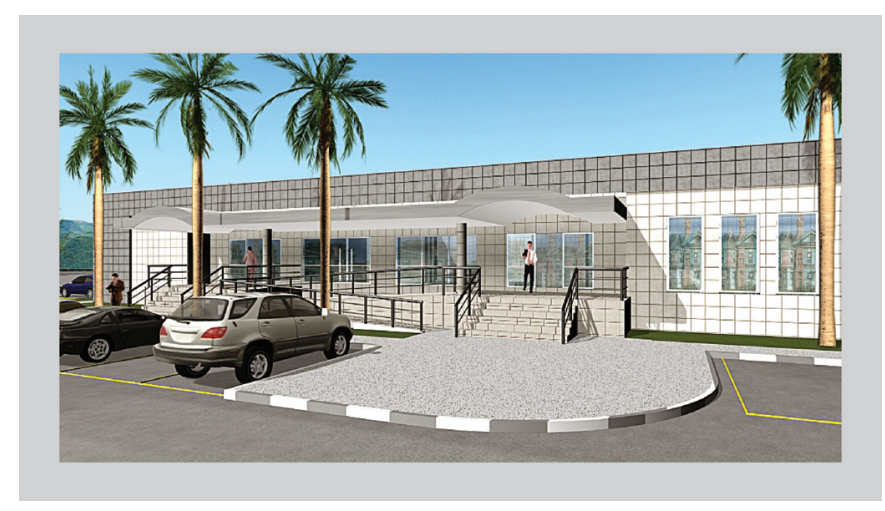

FIGURA 2 - Fachada da divisão de produção de radiofármacos. Fonte: CNEN/CRCN, 2007.

As áreas auxiliares, previstas no ítem 11.2 da norma nacional de projetos fabris (RDC210/03), foram contempladas em sua totalidade, tanto para as salas de descanso que foram devidamente separadas das demais áreas da fábrica, assim como para os vestiários, lavatórios e sanitários, que foram dimensionados conforme as normas nacionais e regionais específicas.

Vários outros aspectos foram debatidos, como as questões de segurança do trabalho e estruturação, contudo não fazem parte do escopo deste trabalho.

\section{CONCLUSÃO}

A análise da legislação sanitária vigente para medicamentos (RDC 210/03), doravante aplicada aos radiofármacos PET, mostra uma situação muitas vezes impraticável e impossibilitante do desenvolvimento de projetos fabris para radiofármacos PET, pois itens específicos, quando aplicados à realidade dos radiofármacos PET não são cabíveis. Em termos de engenharia do projeto, embora haja muitas especificações que por muitas vezes dificultam a execução do plano diretor, ainda há a possibilidade de adequação. Entretanto, mister se faz ressaltar que, para o registro do produto, assim como para rotulagem e ações rotineiras da linha de produção, diretrizes específicas devem ser elaboradas, para que, desta forma, mantenha-se padrões de qualidade compatíveis com o produto, assim como permita a viabilização de projetos fabris de linhas de produção de radiofármacos PET no Brasil.

\section{ABSTRACT \\ Radiopharmacy and radiopharmaceuticals in Brazil: sanitaries aspects related to a project of an industry of PET radiopharmaceuticals}

The increasing use of radiopharmaceuticals for PET
(Positron Emission Tomography) has come to the attention of nuclear medicine staff and regulatory bodies. The aim of this study is to provide a national reference in radiopharmacy that could help all nuclear medicine staff and specially the Brazilian's regulatory bodies focused on the industrial project.

UNITERMS: Radiopharmacy. Radiopharmaceuticals/ production. Radiopharmaceuticals /industrial projects.

\section{REFERÊNCIAS BIBLIOGRÁFICAS}

BRASIL. Resolução - Resolução de Diretoria Colegiada (RDC) no. 210. A Agência Nacional de Vigilância Sanitária estabelece o Regulamento Técnico das Boas Práticas de Fabricação de Medicamentos. Diário Oficial da União, Brasília, n.156, 14 ago.2003. Seção 1.

FALLAIS, C.J; SIVEWRIGHT, S; OGLE, J.R. The radiopharmaceutical industry and european union regulations. Eur. J. Nucl. Med., v.24, n.1, p.77-79, 1997.

FINN, R.D. The search for consistency in the manufacture of pet radiopharmaceuticals. Ann. Nucl. Med., v.13, n.6, p.379-382, 1999.

MATHER, S.J. Innovation in radiopharmacy: progress and constraints? Eur. J. Nucl. Med., v.28, n.4, p.405-407, 2001.

OLIVEIRA, R.S. Produção de radiofármacos no Brasil. Revista Controle de Contaminação, v.8, n.86, p.36-37, 2006.

TEWSON, T.J; KROHN, K.A. Pet radiopharmaceuticals: state-of-the-art and future prospects. Semin. Nucl. Med., v.28, n.3, p.221-234, 1998.

TOCHON-DANGUY, H.J; SACHINIDIS, J.I; EGAN, G.F; CHAN, J.G; BERLANGIERI, S.U; MCKAY, W.J; SCOTT, A.M. Positron emission tomography: radioisotope and radiopharmaceutical production. Australas. Phys. Eng. Sci. Med., v.22, n.4, p.136-144, 1999.

WESTERA, G. European Association of Nuclear Medicine Draft Guidelines for radiopharmacy. Eur. J. Nucl. Med. Mol. Imag., v.30, n.8, BP63-BP72, 2003.

Recebido para publicação em 19 de janeiro de 2007 Aceito para publicação em 11 de dezembro de 2007 